\title{
Influence of Blockchain Adoption on Technology Transfer, Performance and Supply Chain Integration, Flexibility and Responsiveness. A Case Study from IT\&C Medium-Sized Enterprises
}

\author{
Sebastian-Ion CEPTUREANU ${ }^{1}$, Roy CERQUETI ${ }^{2}$, Adriana ALEXANDRU ${ }^{3}$, \\ Doina I. POPESCU ${ }^{1}$, Gurjeet DHESI ${ }^{4}$, Eduard-Gabriel CEPTUREANU ${ }^{1 *}$ \\ ${ }^{1}$ The Bucharest University of Economic Studies, Romana Square, Bucharest, 010374, Romania \\ sebastian.ceptureanu@man.ase; doina.popescu@man.ase.ro; \\ eduard.ceptureanu@man.ase.ro (*Correspondingauthor) \\ ${ }^{2}$ Sapienza University of Rome/London South Bank University, Piazzale Aldo Moro, 5, 00185 Rome, Italy \\ roy.cerqueti@uniroma1.it \\ ${ }^{3}$ National Institute for Research and Development in Informatics, 8-10 Averescu Ave., Bucharest, 011455, Romania \\ adriana.alexandru@ici.ro \\ ${ }^{4}$ London South Bank University, 103 Borough Rd, London SE1 0AA, United Kingdom \\ dhesig@1sbu.ac.uk
}

\begin{abstract}
The aim of this paper is to analyze how blockchain technology can improve supply chain variables and technology transfer in medium-sized enterprises from IT\&C sector. Blockchain technology is expected to enhance the velocity and reliability of business and managerial processes and increase competitiveness of IT\&C companies. The purpose was to see if these combined elements could lead to the generation of competitive advantage, which in turn would influence the firm performance. Based on the study of relevant literature, a conceptual and methodological framework was developed and tested on 383 medium-sized companies from the IT\&C sector, using the Confirmatory Factor Analysis. The results of this study show that blockchain technology positively influences supply chain variables and technology transfer, with direct effects on the firm performance.
\end{abstract}

Keywords: Blockchain, Supply chain management, Technology transfer, IT\&C.

\section{Introduction}

Blockchain is a disruptive technology that can transfigure "business-as-usual" practices. It is a significant source of innovations in business and management by its effects of improvement, and optimization of the business processes.

Blockchain-enabled applications are present across diverse sectors such as business, data management, education, finances, healthcare, industry, IoT, privacy and security.

One of blockchain main applications area is represented by supply chain networks, where this technology leads to an enhancement in visibility and responsability (Kshetri, 2018) in three areas: visibility, optimization, and demand.

As companies are focusing on increased global competitiveness, supply chains are facing new problems and challenges. These include increasing pressure to reduce operational costs, improve quality, improve customer service and ensure continuity of supply (Ceptureanu \& Ceptureanu, 2019). Nowadays, supply chains are characterized by an increased reaction to changes in customer habits, the orientation towards globalization of activities, the integration of distribution and sales channels and the widespread introduction of new communication technologies. Organizations in the supply chains are obliged to constantly restructure and improve their activities and processes in order to increase their efficiency and to satisfy their customers. This requires companies to look beyond their organizational boundaries and evaluate how the resources and capabilities of suppliers and customers can be used to create exceptional value. The supply chain uses modern technology to gain a competitive advantage over competitors. Modern supply chains are becoming complex due to business internationalization, fast growing customer demand and decreased product life cycle. The digitalization of supply chains is a solution for meeting these challenges (Pereira, 2009).

Existing research on supply chain management is characterized by evolving definitions and contradictions (van der Vaart \& van Donk, 2008). While certain researches focus on the individual dimensions of supply chain others use various omnibus definitions, examining supply chain as a single construct. Moreover, 
some conceptualizations of supply chain are incomplete, which has led to inconsistent findings about the relationship between supply chain and performance (Germain \& Iyer, 2006).

In the current economic context, characterized by the internationalization of activities and a tendency to reduce costs, there is a paradigm shift from traditional IT\&C to smart and sustainable IT\&C (Michel, 2017). IT\&C companies are looking for modern information technology solutions to simplify supply processes, coordinate the activities of the supply chain members, and, as a general effect, improve the performance of the company (Scholtz-Reiter et al., 2010; Topal \& Sahin, 2018).

Blockchain offers a greater transparency in transactions between members of the supply chain and synchronization of the processes between the supply chain members and has become a way to achieve competitive advantage (Yli-Huumo et al., 2016). Blockchain technology offers a transactional platform for providing members of the information supply chain with a higher speed, improved accuracy and information sharing possibilities according to knowledge-based company principles, with beneficial effects on improving the distortion, filtering, redundancy and overloading of information circuits between members.

Kshetri (2018) considers that blockchain transactions are much cheaper than by any other equivalent means. The result of this technological architecture is better traceability and resolution of reliability issues among supply chain members. The blockchain academic relevance has already been recognized for supply chain management (SCM) and logistics (Kshetri, 2018). Moreover, a substantial number of researches in the field have already been published that critically investigate the blockchain (Romano \& Schmid, 2017) and its potential applications in the SCM / logistics field (Hackius \& Petersen, 2017). Blockchain can bring about improvements in transactions that can be useful to members of the supply chain (Tapscott et al., 2017). Unfortunately, blockchain has many practical challenges; namely, companies don't invest in employee training, high implementation cost, required dedicated skills, etc. In addition, most of the entrepreneurs involved in supply chain networks are not fully aware of the benefits of the blockchain that can provide a competitive advantage both for the network and to their own companies. Poor understanding of the blockchain concepts and practices is also a reason for a lower adoption rate (Andoni et al., 2019) and empirical evidence is weak (Saberi et al., 2018). The current research will try to fill this gap by linking the blockchain with the supply chain, generating competitive advantages and organizational performance for the small and medium- sized enterprises from IT\&C sector (Chari et al., 2008).

The paper is organized as follows. Section 2 presents an extensive literature review and it outlines the development of hypotheses. Section 3 analyzes the methodology, the measurement model and the structural model. Section 4 analyzes and discusses the main findings and contributions. Finally, Section 5 concludes the paper, while outling limitations and future research pathways.

\section{Literature Review and Hypothesis Development}

\subsection{Blockchain Overview}

A blockchain is a distributed peer-to-peer linked data structure in the format of an append-only timestamped database that is organized as a list of ordered blocks, where the registered blocks are unalterable. The nodes of the network are linking the blocks to each other in chronological order, every block containing the hash of the previous block (Crosby et al., 2016). The resulting distributed peer-to-peer network allows the interaction of any members without the need for a trusted authority (Christidis \& Devetsikiotis, 2016). To achieve this one can consider blockchain as a set of interconnected mechanisms which provide specific features to the infrastructure, as it is illustrated in Figure 1 (Casino et al., 2019), where:

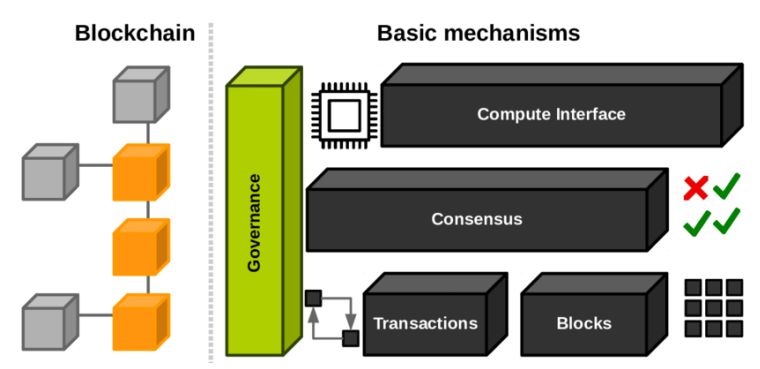

Figure 1. Blockchain architecture 
- $\quad$ The lowest layer consists of:

- Transactions between peers that indicate an agreement between two participants for transferring physical or digital assets, completing a task, etc. A transaction is signed by minimally one participant, and it is disseminated to its neighbors;

- A node represents an entity connected to the blockchain. The nodes that control all the rules in the blockchain are called full nodes. Their role is to group the transactions into blocks and to establish the valid transactions that have to be kept in the blockchain.

- Consensus layer has the goal to keep in the blockchain only the transactions agreed by the nodes and which will not corrupt branches or cause divergences (Vukolić, 2015; Christidis \& Devetsikiotis, 2016). There are several consensus approaches depending on the blockchain type (Mingxiao et al., 2017): Proofof-Work (PoW) (Antonopoulos, 2014), Proofof-Stake (PoS) (Pilkington, 2016), Byzantine Fault Tolerance (BFT) (Castro and Liskov, 2002) and its variants (Zheng et al., 2016).

- Computer Interface layer provides blockchain with an enhanced functionality by storing simple or complex states and allowing (advanced) applications to provide information to the users

- Governance layer extends the blockchain architecture to cover the human interactions taking place in the physical world. It deals with how diverse actors from the physical world come together to produce, maintain, or change the inputs that make up a blockchain.

\subsection{Connections Between Blockchain Technology, Information Systems and Supply Chain}

Recent studies have focused on effects associated with use of information systems in supply chains. There is evidence that supply chain coordination and integration are facilitated by the use of integrated information technologies (Vickery et al., 2003) and IT\&C integration capabilities (Rai et al., 2006), and lead to improved firm performance. Shah et al. (2002) suggests that supply chain practices such as supply chain integration, and initiatives such as building long-term relationships with suppliers, require extensive use of webbased interchange; and thus the support of inter- organizational information systems. Arguing that supply chains at different levels of integration and coordination require different levels of technology integration, it propose a conceptual framework suggesting that a high or low level of supplier integration must be matched with a high or low level of IT\&C integration in order to achieve superior supply chain performances. Premkumar et al. (2005) examines procurement- related information processing needs (from uncertainties in the product market environment and supplier relationships) and information processing capabilities (through the deployment of electronic procurement applications), and uses the theory of Galbraith (1973) to show that aligning the two enhances supply chain performance. Thus, it is increasingly being recognized that the design of supply chains should include consideration of corresponding and specific information processing requirements and accompanying implications for deploying particular information systems. The supply chain literature however is largely deficient in frameworks that might facilitate such an analysis.

How blockchain functions within the context of the supply chain are still open to interpretation and development. Blockchain-based supply chain networks usually require a closed, private, permissioned blockchain with multiple, limited players. But that doesn't mean that the door may still be open for a more public set of relationships. Privacy level determination is one of the initial decisions. According to Khan \& Salah (2018), blockchain technology is expected to enhance the velocity and reliability of business and managerial processes. Also, it is useful in making a more precise demand forecast, inventory management, back-up at demand disruption and reducing informational distortion, filtering, redundancy and overloading of informational channels (Tjahjono et al., 2017) (see Figure 2).

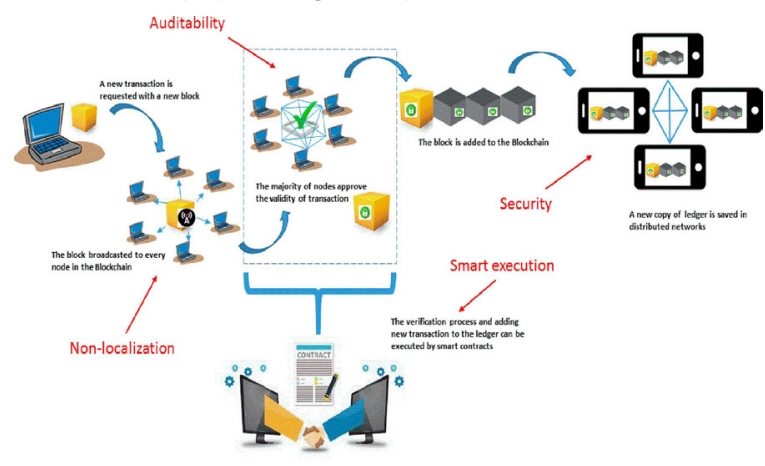

Figure 2. Steps in blockchain information and transactions 
The role of blockchain in the supply chain will continue to be a key issue among researchers (Grover \& Kohli, 2012). The main issues to be solved involve sharing/transaction of information and knowledge between supply chain members with reliability, velocity and accuracy, using advanced cloud environments (Wang et al., 2012; Popescu et al., 2018). Blockchain can be connected with elaborate IT applications such as IoT, big data, artificial intelligence and analyse the data generated by business operations (Wu et al., 2006). According to Reinartz et al. (2004) blockchain impacts both supply chain process and business/managerial transactions between different network parties. One of the most important advantages of blockchain supply chain is the disintermediation of intermediaries (Reinartz et al., 2004). This will make trading processes among partners more efficient. Reduced effectiveness and efficiency in supply chain flows can be improved through supply chain instruments and techniques (Grover et al., 2012) saving networks millions of euros (Hofmann et al., 2018).

\subsection{Technology Transfer (TT)}

Technology transfer is a process of dissemination or retention of technologies, relevant knowledge, and the outcomes of its implementation. It generates products or other elements for the involved parties, which may include industries, individuals, institutions, or entities (Carlsson et al., 1992).

The complexity of this type of transfer process has been examined by a growing number of researchers whose findings are beginning to impact upon technology policy decision-making (da Silva et al., 2018; Nicotra et al., 2018). The nature of the interactive process of transfer has been evolving from a relatively simple version relating the interactions between a supplier and a receiver of technology to more complex variants involving multiple actors and influences (Friedman \& Silberman, 2003; Gopalakrishnan \& Santoro, 2004; Barge-Gil \& Modrego, 2011). More recently, intangible assets, like an idea, knowledge, experience, or a software are being taken into account (Jedlitschka et al., 2007; Günsel, 2015). Therefore, it can be hypothesized that blockchain will improve reliability which will result in better firm performance.

H1. Technology transfer generated by using blockchain technology leads to better firm performance on IT\&C MSES.

\subsection{Supply Chain Responsiveness (RE)}

Supply chain responsiveness refers to "the ability of the firm to adapt according to market change in terms of strategies, products and technologies" (Mentzer et al., 2011). Supply chain responsiveness is introduced as a primary desired performance outcome from these relationships by purchasing organizations (Qrunfleh \& Tarafdar, 2013). In structuring these relationships with a view to improving responsiveness, entrepreneurs may require suppliers to comply with certain requirements for instance detailed written contracts, dedicated human or capital assets, in order to support the relationship (Handfield \&Bechtel, 2002). However, the degree to which the supplier is willing to agree with these requirements is tempered by the level of power the supplier has over the buyer (Doney \& Cannon, 1997). Blockchain has the ability to rapidly integrate all processes in the supply chain and is helpful in achieving a more accurate forecasting of demand, stock management and backup generation as the market situation changes (Tjahjono et al., 2017). Also, the blockchain creates new ways of adapting the company to the changes in the market through the rapid change of the suppliers, the design of the products and services created, as well as changes in the structure of the processes carried out by the organization (Williams et al., 2013). In addition, all quality documents can be standardized and shared with all members of the supply chain that improve decision making (Abeyratne \& Monfared, 2016). Recent research confirms the orientation of companies towards the integration of IT\&C processes with blockchain (Lin et al., 2018). Similarly, logistics can be better managed by the blockchain. There are vehicle tracking devices, such as GPSs, that can be integrated with the blockchain. Therefore, the following can be hypothesized: 
H2. The improved reactivity of the improved blockchain supply chain of a company leads to a competitive advantage for IT\&C MSE.

\subsection{Supply Chain Integration (I)}

Despite the numerous conceptual and empirical papers within the field of SCM, there are neither well-established definitions, nor constructs and scales that unambiguously measure supply chain integration. Frohlich \& Westbrook (2001) stated "Our knowledge is relatively weak concerning which forms of integration companies use to link up with suppliers and customers". Similar statements have been made in a number of review papers regarding definitions of supply chain integration or related to its measurement and constructs (Giannakis et al., 2004). There are many different interpretations, types and classifications of supply chain integration. van der Vaart et al. (2008) distinguished over 20 constructs that have been used to measure supply chain integration in survey research. A well-known distinction is between internal and external integration (Giménez et al., 2005). Another distinction is between upstream and downstream integration - integration with suppliers or buyers (Flynn et al., 2010). In specialized literature, supply chain integration has been analyzed from different perspectives (van der Vaart et al., 2008). Some authors have analysed integration with suppliers and customers (Salvador et al., 2001; Gunasekaran, et al., 2004). Others have focused on upstream integration, analyzing the integration with suppliers (Chiou et al., 2011). A final group of authors has analysed the integration with buyers (Giménez et al., 2005; Rai et al., 2006; Prajogo et al., 2012).

Blockchain has the capacity to integrate all supply chain processes of member partners and also increases the speed of execution of business processes with greater accuracy and reliability (Salvador et al., 2001). Hence, it can be hypothesized that:

H3. Blockchain-enhanced supply chain integration of a firm leads to competitive advantage for IT\&C MSES.

\subsection{Supply Chain Flexibility (F)}

Most of the previous research on flexibility has focused on internal IT\&C flexibility. The components of IT\&C flexibility play an important role in supply chain flexibility (Ueno et al., 2017; Shishodia et al., 2019; Nguyen et al., 2020). However, as the supply chain extends beyond the company, supply chain flexibility must also extend beyond a firm's internal flexibility (Park et al., 2017; Yu et al., 2017; Tipu et al., 2019). Flexibility is the ability of the supply chain to meet with unexpected changes in the market demand and convert them into business opportunities (Vickery et al., 2003). A limited number of authors have begun to discuss flexibility from a supply chain perspective. For instance, in the paper on matching the supply chain to the marketplace, Mason-Jones et al. (2000) highlighted the importance of matching supply chain improvement initiatives to customer demand. Others stress the importance of combining the lean concepts of eliminating waste with the flexibility concepts of exploiting opportunities in a volatile market (Soon \& Udin, 2011; Dey et al. 2019). Vickery et al. (2003) defined five supply chain flexibilities based on previous literature of operations - product and volume flexibility, new product flexibility, distribution flexibility and responsiveness flexibility. The authors state that supply chain flexibility should be examined from an integrative, customer-oriented perspective. Flexibilities viewed as directly impacting a firm's customer- and the responsibility of two or more functions, whether internal or external to the firm, are included (Tjahjono et al., 2017). Therefore, it can be hypothesized that:

H4. Blockchain-enhanced supply chain flexibility of a firm leads to competitive advantage for IT\&C MSES.

Dynamic capabilities are important intangible resources that enable businesses to generate performance in a changing environment (Pezeshkan et al., 2016), where product and business model life cycles is short (Svensson, 2000). Hence, firms need to constantly search for new opportunities (Prahalad \& Krishnan, 2008). Integration, responsiveness and flexibility are 
important capabilities which give a competitive advantage (Mentzer et al., 2011). Dynamic capabilities of the firm are intangible and valuable resources which can generate/explain firm competitiveness. They also enable mediumsized enterprises to create, allocate and protect the intangible assets that support superior long run business performance (Winter, 2003). Previous studies (Dyer \& Singh, 1998) have shown that improvement in competitive advantage generates superior firm performance. Hence:

H5. Competitive advantage generated by blockchain technology positively affects MSEs performance.

Based on literature review a conceptual model is proposed in Figure 3:

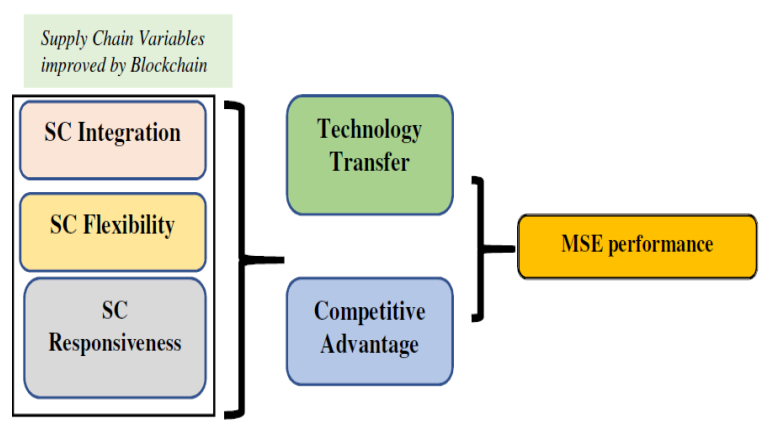

Figure 3. The proposed conceptual model

\section{Methodology and Results}

The present study sought responses from entrepreneurs from Romanian medium-sized enterprises (enterprises who fulfil at least one of the following criteria: a) staff headcount between 50-249 employees; b) turnover of less than 50 milion EUR; c) balance sheet total $<34$ milion EUR) from IT\&C sector. The responses from the participants were collected via an email survey, and the participation was kept voluntary with follow up emails, with the support of Romanian National Institute of Statistics (RNIS). From a sample of 583 entrepreneurs from Romanian IT\&C MSEs, after data collection and initial analysis, 383 valid responses were obtained which were used for further analysis. The survey period lasted for more than sixteen months from September $5^{\text {th }}, 2018$ to December $10^{\text {th }}, 2019$.

The questionnaire was developed in the English language and the statements measuring all the constructs were anchored on five-point Likert scale. The questionnaire comprised 36 questions, with the first section comprising general questions regarding the companies involved in the study (5 questions); the second section comprised questions regarding the objective of the study (26 questions); finally, the last section covered the recommendations (5 questions). The scales were subjected to content validity. Although, the items used were adopted from the previous studies and were modified for studying blockchain effect on these constructs, still, it was pretested with subject experts to ensure that questions were relevant with respect to blockchain technology implementation in the supply chain. The measures used and their sources are shown in Table 1.

\subsection{Measurement Model}

An older version of IBM SPSS AMOS (v24) was used in order to conduct CFA with the aim of obtaining information on convergent validity, compound reliability and discriminant validity of the measures used.

Firstly, confirmatory factor analysis was conducted to get information about convergent validity, composite reliability and discriminant validity of the measures used. The six constructs demonstrate satisfactory convergent validity, all the factor loadings are statistically significant (Table 1).

The fit indices (CFI - comparative fit index, RMSEA - root mean square error of approximations) of the measurement model are also within the acceptable limits as per Hair et al. (2017) (Table 2).

Table 2. Fit indices for the measurement model

\begin{tabular}{ccccc}
\hline $\begin{array}{c}\text { Fit index } \\
\text { Acceptable }\end{array}$ & CFI & TLI & RMSEA & PCLOSE \\
$\begin{array}{c}\text { value } \\
\begin{array}{c}\text { Obtained } \\
\text { value }\end{array}\end{array}$ & 0.960 & 0.957 & 0.044 & 0.690 \\
\hline
\end{tabular}

Table 4 shows the average variance extracted and composite reliability for all the constructs.

Discriminant validity was checked by comparing the square roots of the AVEs with the correlation for each of the constructs, using the Fornell and 
Table 1. Confirmatory factor analysis

\begin{tabular}{|c|c|c|c|}
\hline Variables & Source of items used & Items & $\begin{array}{l}\text { Factor loading } \\
\text { (standardized) }\end{array}$ \\
\hline \multirow{8}{*}{ SC flexibility (F) } & Ueno et al. (2017) & F1: BKC increases product/service customization & 0.652 \\
\hline & Nguyen et al. (2020) & F2: BKC increase volume flexibility & 0.629 \\
\hline & Shishodia et al. (2019) & $\begin{array}{l}\text { F3: BKC improves incidence of introducing new } \\
\text { product/service }\end{array}$ & 0.617 \\
\hline & Tipu \& Fantazy (2019) & F4: BKC reduces R\&D time & 0.661 \\
\hline & Park et al. (2017) & F5: BKC adjusts market needs & 0.620 \\
\hline & Yu et al. (2017) & F6: BKC increase customer service & 0.619 \\
\hline & Dey et al. (2019) & $\begin{array}{l}\text { F7: BKC reduce product/service development } \\
\text { cycle time }\end{array}$ & 0.609 \\
\hline & Soon \&Udin (2011) & F8: BKC increase delivery capabilities & 0.631 \\
\hline \multirow{4}{*}{ SC integration (I) } & $\begin{array}{l}\text { Gunasekaran \& Ngai } \\
\text { (2004) }\end{array}$ & $\begin{array}{l}\text { I1: Process integration capability will be } \\
\text { ameliorated by using BKC }\end{array}$ & 0.696 \\
\hline & Flynn et al. (2010) & $\begin{array}{l}\text { I2: Integration management, logistics and other } \\
\text { internal areas capabilities will be ameliorated by } \\
\text { using BKC }\end{array}$ & 0.825 \\
\hline & $\begin{array}{l}\text { Prajogo \& Olhager } \\
\qquad(2012)\end{array}$ & $\begin{array}{l}\text { I3: Face-to-face communication with internal } \\
\text { and external stakeholders will be ameliorated by } \\
\text { using BKC }\end{array}$ & 0.878 \\
\hline & Rai et al. (2006) & $\begin{array}{l}\text { I4: In coordinating the specific activities or } \\
\text { exchanging information with stakeholders } \\
\text { formal and informal communication channels are } \\
\text { followed and this will be improved by using BKC }\end{array}$ & 0.683 \\
\hline \multirow{3}{*}{$\begin{array}{l}\mathrm{SC} \text { responsiveness } \\
(\mathrm{RE})\end{array}$} & $\begin{array}{l}\text { Handfield \& Bechtel } \\
\text { (2002) }\end{array}$ & $\begin{array}{l}\text { RE1: Short lead-times per market requirements } \\
\text { by using BKC }\end{array}$ & 0.742 \\
\hline & Williams et al. (2013) & $\begin{array}{l}\text { RE2: Outstanding on-time delivery record by } \\
\text { using BKC }\end{array}$ & 0.788 \\
\hline & $\begin{array}{l}\text { Qrunfleh \& Tarafdar } \\
\qquad(2013)\end{array}$ & $\begin{array}{l}\text { RE3: Ability to modify products/services to meet } \\
\text { requirements by using BKC }\end{array}$ & 0.781 \\
\hline \multirow{4}{*}{$\begin{array}{l}\text { MSE performance } \\
\text { (MSEP) }\end{array}$} & Hudson et al. (2001) & $\begin{array}{l}\text { MSEP1: Service level will be ameliorated by } \\
\text { using BKC }\end{array}$ & 0.719 \\
\hline & Bahri et al. (2011) & $\begin{array}{l}\text { MSEP2: Operation cost of supply chain processes } \\
\text { will be reduced by using BKC }\end{array}$ & 0.608 \\
\hline & Sidik (2012) & $\begin{array}{l}\text { MSEP3: Added value creation in the supply chain } \\
\text { will be enhanced by using BKC }\end{array}$ & 0.692 \\
\hline & Michna, A. (2009) & $\begin{array}{l}\text { MSEP4: Rapidity of supply chain operations will } \\
\text { be enhanced by using BKC }\end{array}$ & 0.547 \\
\hline \multirow{4}{*}{$\begin{array}{l}\text { Technology Transfer } \\
\text { (TT) }\end{array}$} & $\begin{array}{l}\text { Barge-Gil \& Modrego } \\
\text { (2011) }\end{array}$ & TT1: BKC positively influences Research Phase & 0.958 \\
\hline & Nicotra et al. (2018) & $\begin{array}{l}\text { TT2: BKC positively influence } \\
\text { Development Phase }\end{array}$ & 0.978 \\
\hline & $\begin{array}{l}\text { Friedman \& Silberman } \\
\qquad(2003)\end{array}$ & TT3: BKC provides benefits on Production Phase & 0.956 \\
\hline & $\begin{array}{l}\text { Jedlitschka et al. } \\
\text { (2007) }\end{array}$ & $\begin{array}{l}\text { TT4: BKC reduce probability of unsuccessful } \\
\text { technology transfer }\end{array}$ & 0.960 \\
\hline \multirow{3}{*}{$\begin{array}{l}\text { Competitive advantage } \\
\text { (C) }\end{array}$} & $\begin{array}{l}\text { Flamholtz \& Randle } \\
\text { (2012) }\end{array}$ & $\begin{array}{l}\mathrm{C} 1: \mathrm{BKC} \text { will help to ameliorate capability to } \\
\text { respond according to customer needs }\end{array}$ & 0.970 \\
\hline & Sigalas et al. (2013) & $\begin{array}{l}\mathrm{C} 2 \text { : BKC will improve capability to integrate } \\
\text { internal and external processes }\end{array}$ & 0.958 \\
\hline & Chiou, T.Y. (2011) & $\begin{array}{l}\text { C3: It will become easier to capitalize on } \\
\text { opportunities and competitive advantage } \\
\text { to the firm }\end{array}$ & 0.941 \\
\hline
\end{tabular}


Larcker criterion (1981). The square root AVE of the selected construct should be higher than the correlations between a construct and all the other constructs in the model. The diagonal items in Table 3 represent the square roots of AVEs, which are measures of variance between the construct and its indicators, and the off-diagonal items represent the correlation between constructs. It can be noticed from Table 3 that the square root of AVE is higher than the correlation between the constructs which indicates that all the constructs exhibit discriminant validity. The measurement model obtained is shown in Figure 4.

Table 3. Discriminant validity

\begin{tabular}{lcccccc}
\hline Variables & A & B & C & D & E & F \\
$\begin{array}{c}\text { A. Supply chain } \\
\text { flexibility }\end{array}$ & $\mathbf{0 . 7 4 2}$ & & & & & \\
$\begin{array}{c}\text { B. Supply chain } \\
\text { integration }\end{array}$ & 0.181 & $\mathbf{0 . 8 7 3}$ & & & & \\
$\begin{array}{c}\text { C. Supply chain } \\
\text { responsiveness }\end{array}$ & 0.288 & 0.371 & $\mathbf{0 . 8 7 6}$ & & & \\
$\begin{array}{c}\text { D. MSE } \\
\text { performance }\end{array}$ & 0.475 & 0.294 & 0.163 & $\mathbf{0 . 7 9 8}$ & & \\
$\begin{array}{c}\text { E. Technology } \\
\text { Transfer }\end{array}$ & 0.101 & 0.181 & 0.247 & 0.247 & $\mathbf{0 . 8 5 0}$ & \\
$\begin{array}{c}\text { F. Competitive } \\
\text { advantage }\end{array}$ & 0.253 & 0.287 & 0.320 & 0.345 & 0.318 & $\mathbf{0 . 9 5 7}$ \\
\hline
\end{tabular}

Composite reliability of all the constructs is higher than 0.70 and average variance extracted is higher than 0.50 (Hair et al., 2017) (Table 4). Table 4 shows the average variance extracted and composite reliability for all the constructs.

Table 4. Reliability

\begin{tabular}{cccc}
\hline Variables & AVE & CR & $\begin{array}{c}\text { Cronbach's } \\
\text { alpha }\end{array}$ \\
$\begin{array}{c}\text { Supply chain } \\
\text { flexibility }\end{array}$ & 0.552 & 0.8039 & 0.8415 \\
$\begin{array}{c}\text { Supply chain } \\
\text { integration }\end{array}$ & 0.771 & 0.8580 & 0.8522 \\
$\begin{array}{c}\text { Supply chain } \\
\text { responsiveness }\end{array}$ & 0.772 & 0.8172 & 0.8153 \\
$\begin{array}{c}\text { MSE performance } \\
\text { Technology }\end{array}$ & 0.641 & 0.7400 & 0.7402 \\
Transfer & 0.724 & 0.9699 & 0.9821 \\
$\begin{array}{c}\text { Competitive } \\
\text { advantage }\end{array}$ & 0.957 & 0.9720 & 0.9718 \\
\hline
\end{tabular}

Table 5 outlines the descriptive statistics (mean and standard deviation) for each of the variables. The structural model is shown in Figure 5.

\subsection{Structural Model Analysis}

The next table illustrates the results of the structural model analysis for testing the hypotheses

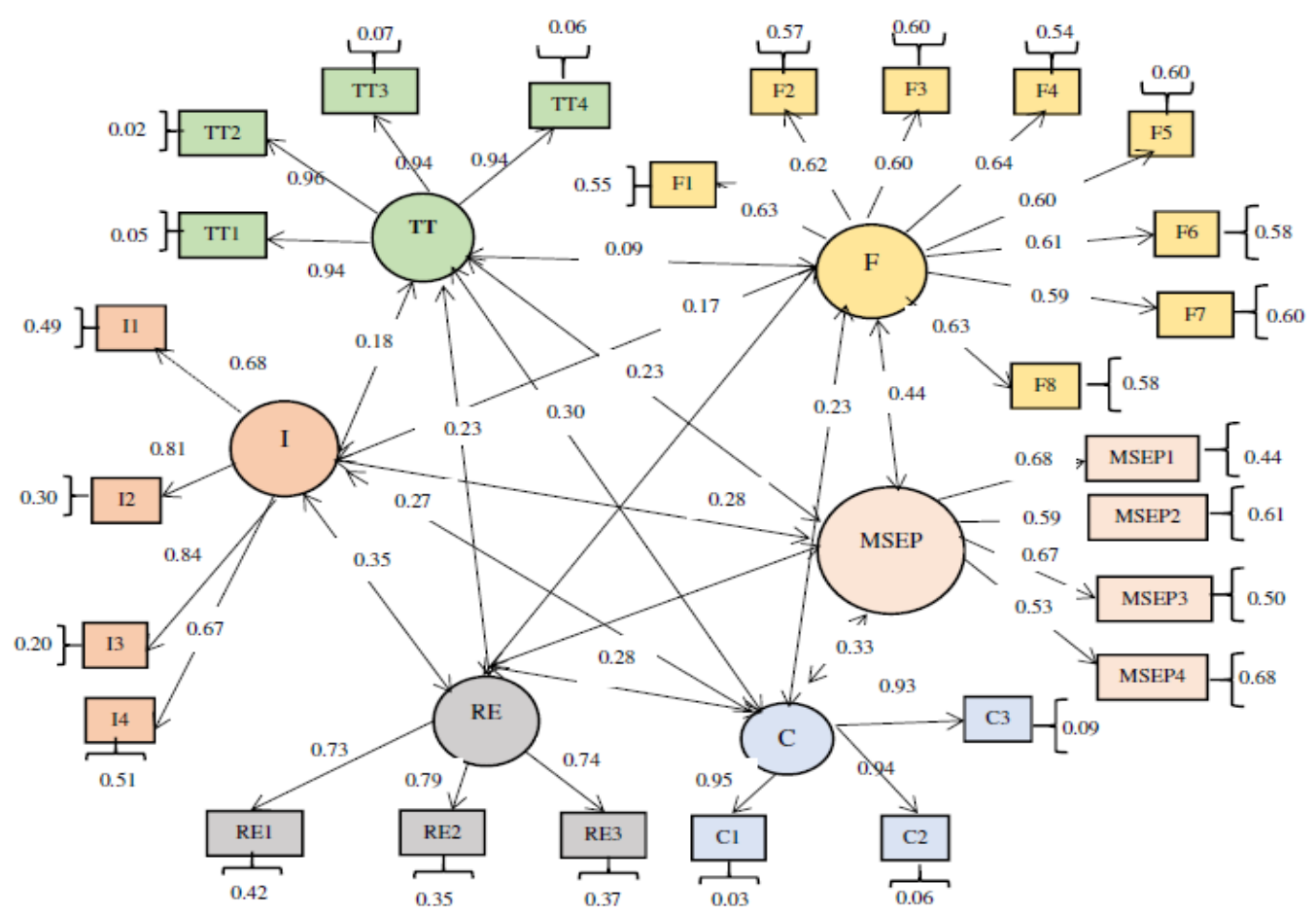

Figure 4. Measurement model 


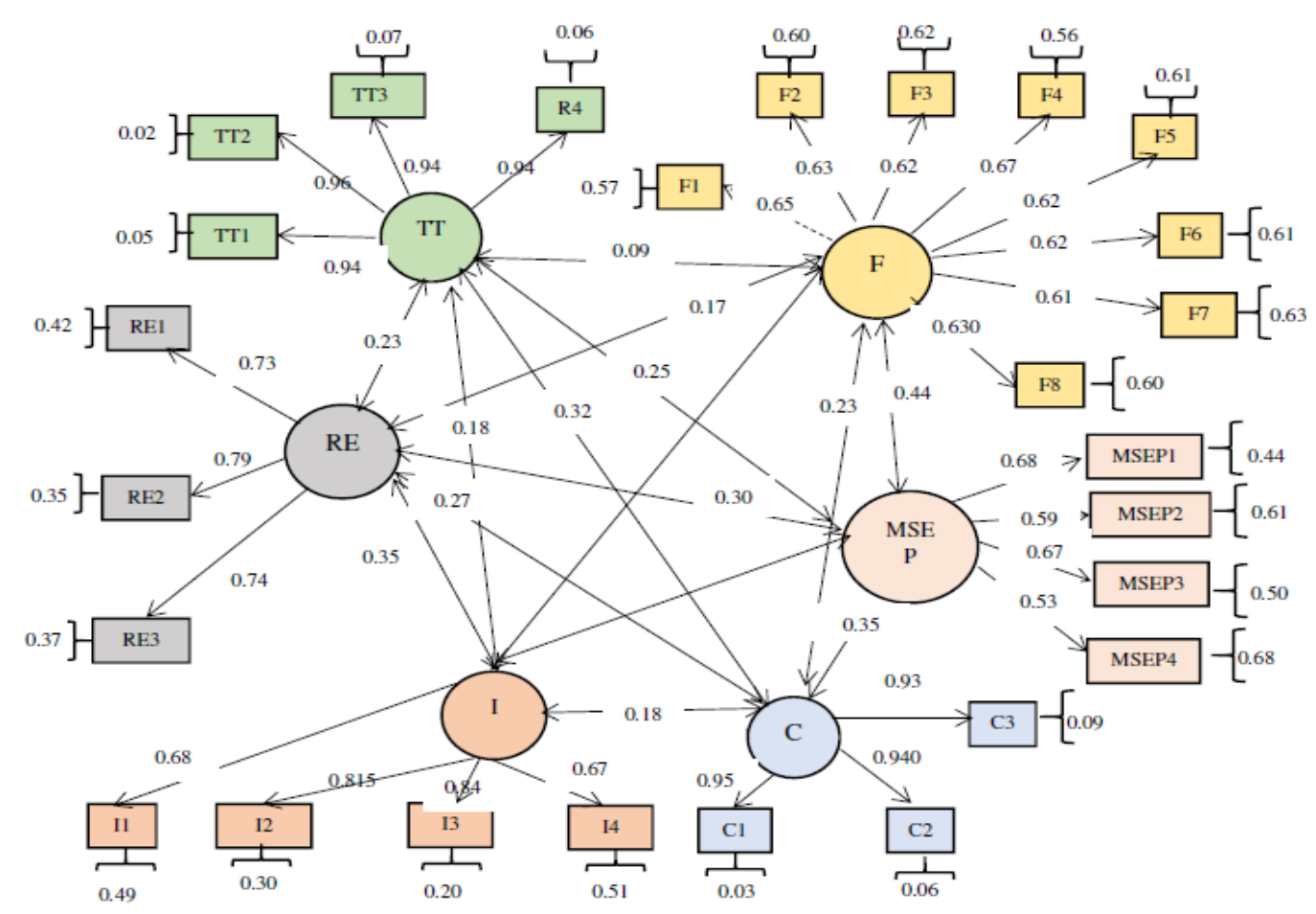

Figure 5. Structural model

of the current study and summarizes the results of the path analysis and hypothesis testing result.

The structural model has an overall acceptable fit with CFI: 0.952; RMSEA: 0.052; PCLOSE: 0.123 , indicating that the proposed model fits the observed data well (Hair et al., 2017). All five hypotheses are accepted $(\mathrm{p}<0.05)$ (see Table 6).

Table 5. Descriptive statistics

\begin{tabular}{ccc}
\hline Variables & Mean & $\begin{array}{c}\text { Standard } \\
\text { deviation }\end{array}$ \\
$\begin{array}{c}\text { Supply chain flexibility } \\
\text { Supply chain integration }\end{array}$ & 4.023 & 0.6051 \\
$\quad \begin{array}{c}\text { Supply chain } \\
\text { responsiveness }\end{array}$ & 4.253 & 0.6171 \\
MSE performance & 3.943 & 0.6672 \\
Technology Transfer & 4.282 & 0.6556 \\
Competitive advantage & 4.410 & 0.6970 \\
\hline
\end{tabular}

The results of the analysis of the structural model are presented in Table 6 .

\section{Discussion and Contributions}

The results of data analysis (Table 6, Figure 5) shows that blockchain-enhanced supply chain variables such as supply chain integration $(0.189$, $\mathrm{p}<0.05)$; supply chain responsiveness $(0.207$, $\mathrm{p}<0.05)$ and supply chain flexibility $(0.161$, $\mathrm{p}<0.05$ ) are having a significant positive effect on competitive advantage of a company.

It means the entrepreneurs have a perception that blockchain will help them make their business competitive by reducing R\&D times and development cycle, improving incidence of introducing new product/services, increasing product/service customization and delivery capabilities, increase customer service, volume flexibility and adjusting changing market needs. As integration is concerned, entrepreneurs are also certain that by adopting the blockchain

Table 6. Structural model analysis

\begin{tabular}{ccccccc}
\hline Hypothesis & Path & Estimate & Std. Error & $\mathbf{z}$ & Sig. & Result \\
$H 1$ & MSEP- TT & 0.149 & 0.049 & 2.953 & 0.003 & Accepted \\
$H 2$ & C-RE & 0.207 & 0.056 & 3.601 & 0.000 & Accepted \\
$H 3$ & C-I & 0.189 & 0.057 & 3.218 & 0.001 & Accepted \\
$H 4$ & C-F & 0.161 & 0.055 & 2.898 & 0.004 & Accepted \\
$H 5$ & MSEP- C & 0.327 & 0.062 & 5.173 & 0.000 & Accepted \\
\hline
\end{tabular}


technology they will be more able to improve integration management, to integrate process, logistics and other internal capabilities, as well as direct communication with internal and external stakeholders. With regard to responsiveness, it is obvious that entrepreneurs hold the perception that adopting blockchain technology will help them to obtain a better on-time delivery record, improve their ability to modify services/products to meet requirements and obtain short lead-times per market requirements. Overall, it can be concluded that entrepreneurs have high hopes of efficiency with regard to using blockchain-based IT applications in the supply chain. Responsiveness, integration and flexibility are essential elements which provide a competitive advantage to an organization Consequently, blockchain improves competitive advantage for an organization.

Technology transfer generated by using blockchain is also having a significant positive effect on firm performance $(0.149 \mathrm{p}<0.05)$. As the result indicate, the entrepreneurs have the perception that the adoption of blockchain technology will help them increase technology transfer, they will have better traceability of research, development and production phases and reduce probability of unsuccessful technology transfer which may lead to a better firm performance.

This study has contributed to literature in couple of ways. To date, there is no empirical study in Romania which connects blockchain with supply chain performance variables. The present model connecting integration, flexibility and responsiveness is new, the overall fit is satisfactory (CFI: 0.960, RMSEA: 0.044) and it was developed by authors after a comprehensive literature review. Future studies should probe in detail specific supply chains on how blockchain technology can improve such supply chains.

\section{Conclusions, Limitations and Future Research}

This paper may contribute to the development of specialized literature in multiple ways. To date, there is no empirical study linking blockchain, technology transfer with supply chain integration, flexibility and responsiveness in order to generate competitive advantage and organizational performance. The findings of the current analysis indicate that MSEs should increase cooperation with IT companies committed to developing blockchain-based supply chain solutions so that the expectations of supply chain decision makers could be met with respect to blockchain technology and its utility for managing the supply chain. (Abeyratne \& Monfared, 2016). The present paper could increase decision makers' interest in the associated technologies, like IoT or Big Data, to improve its application. Finally, supply chain decision makers and IT companies wishing to embrace and develop blockchain-based IT solutions for the supply chain should start pressuring regulatory actors to develop a legal framework for controlling blockchain technology. To date, shy attempts have been made to regulate this domain in Romania, through the United Blockchain Association Romania, but unfortunately the results are not satisfactory. Without a legal framework, technology will remain very risky in terms of adoption. Entrepreneurs, managers, as well as IT\&C companies involved in design and implementation of the supply chain management system , as well as academics should increase cooperation in order to study and develop a framework for regulating blockchain technology and suggest possible improvements to policy makers.

This study has a number of limitations that could be resolved in future research. First, respondents do not have / have very little practical experience in using blockchain technology. Their responses were based on their knowledge of the blockchain which they obtained from various public sources. Second, the present study presumes that government regulations on blockchain technology are favorable and that all regulatory frameworks are created with a view to supporting blockchain technology. However, in Romania, at present, there is no official framework for regulating and governing blockchain technology and its applications. Finally, the study targets mediumsized firms in the production sector, where blockchain technology is in the early stages of its implementation. More developed are the financial services and trade sectors. However, important steps are being taken in the production sector for implementing these modern technologies.

The effects of the blockchain on the important variables of the supply chain should be studies further on. The effects of the blockchain on the important variables of the supply chain should be studied further on through longitudinal studies or by the integration of the blockchain with IoT, RFID, Big Data and artificial intelligence studied. 


\section{Acknowledgements}

This work is supported by a grant of the Romanian National Authority for Scientific Research and Innovation, CNDS-UEFISCDI, project number PN-III-P1-1.1-TE-2019-1188.

\section{REFERENCES}

Abeyratne, S. A. \& Monfared, R. P. (2016). Blockchain ready manufacturing supply chain using distributed ledger, International Journal of Research in Engineering and Technology, 5(9), 1-10.

Andoni, M., Robu, V., Flynn, D., Abram, S., Geach, D., Jenkins, D., McCallum, P. \& Peacock, A. (2019). Blockchain technology in the energy sector: A systematic review of challenges and opportunities, Renewable \& Sustainable Energy Reviews, 100, 143-174.

Antonopoulos, A. M. (2014). Mastering Bitcoin: Unlocking Digital Cryptocurrencies. O'Reilly Media Inc.

Bahri, M., St-Pierre, J. \& Sakka, O. (2011). Economic value added: a useful tool for SME performance management, International Journal of Productivity and Performance Management, 60(6), 603-621.

Barge-Gil, A. \& Modrego, A. (2011). The impact of research and technology organizations on firm competitiveness. Measurement and determinants, Journal of Technology Transfer, 36(1), 61-83. DOI: 10.1007/s10961-009-9132-4

Carlsson, B. \& Jacobsson, S. (1992). Technological Systems and Economic Policy: The Diffusion of Factory Automation in Sweden, Research Policy, 23(3), 235-248.

Casino, F., Dasaklis, T. K. \& Patsakis, C. (2019). A systematic literature review of blockchain-based applications: Current status, classification and open issues, Telematics and Informatics, 36, 55-81.

Castro, M. \& Liskov, B. (2002). Practical Byzantine fault tolerance and proactive recovery, $A C M$ Transactions on Computer Systems (TOCS), 20(4), 398-461.

Ceptureanu, E. G. \& Ceptureanu, S. I. (2019). The impact of adoptive management innovations on medium-sized enterprises from a dynamic capability perspective, Technology Analysis \& Strategic Management, 31(10), 1137-1151.

Chari, M. D. R., Devaraj, S. \& David, P. (2008). Research note- the impact of information technology investments and diversification strategies on firm performance, Management Science, 54(1), 224-234.
Chiou, T. Y., Chan, H. K., Lettice, F. \& Chung, S. H. (2011). The influence of greening the suppliers and green innovation on environmental performance and competitive advantage in Taiwan, Transportation Research Part E - Logistics and Transportation Review, 47(6), 822-836.

Christidis, K. \& Devetsikiotis, M. (2016). Blockchains and Smart Contracts for the Internet of Things, IEEE Access, 4, 2292-2303.

Crosby, M., Pattanayak, P., Verma, S. \& Kalyanaraman, V. (2016). Blockchain technology: beyond bitcoin, Applied Innovation Review, 2, 6-10.

da Silva, V. L., Kovaleski, J. L \& Pagani, R. N. (2018). Technology transfer in the supply chain oriented to industry 4.0: a literature review, Technology Analysis \& Strategic Management, 31(5), 546-562.

Dey, S., Sharma, R. R. K. \& Pandey, B. K. (2019). Relationship of Manufacturing Flexibility with Organizational Strategy, Global Journal of Flexible Systems Management, 20(3), 237-256.

Doney, P. M. \& Cannon, J. P. (1997). An examination of the nature of trust in buyer-seller relationships, Journal of Marketing, 61(2), 35-51.

Dyer, J. \& Singh, H. (1998). The relational view: cooperative strategy and sources of interorganizational competitive advantage, Academy of Management Review, 23(4), 660-679.

Flamholtz, E. G. \& Randle, Y. (2012). Corporate culture, business models, competitive advantage, strategic assets and the bottom line: Theoretical and measurement issues, Journal of Human Resource Costing \& Accounting, 16(2), 76-94.

Flynn, B. B., Huo, B. \& Zhao, X. (2010). The impact of supply chain integration on performance: a contingency and configurational approach, Journal of Operations Management, 28(1), 58-71.

Friedman, J. \& Silberman, J. (2003). University Technology Transfer: Do Incentives, Management, and Location Matter?, The Journal of Technology Transfer, 28(1), 17-30.

Frohlich, M. T. \& Westbrook, R. (2001). Arcs of integration: an international study of supply chain 
strategies, Journal of Operations Management, 19(2), 185-200.

Galbraith, J. R. (1973). Designing Complex Organizations, Reading, Mass. Addison-Wesley Pub. Co.

Germain, R. \& Iyer, K. N. S. (2006). The interaction of internal and downstream integration and its association with performance, Journal of Business Logistics, 27(2), 29-53.

Giannakis, M., Croom, S. \& Slack, N. (2004). Supply chain paradigms. In New, S. \& Westbrook, R. (eds.), Understanding Supply Chains: Concepts, Critiques and Futures, 1-22. Oxford. Oxford University Press.

Giménez, C. \& Ventura, E. (2005). Logisticsproduction, logistics-marketing and external integration: their impact on performance, International Journal of Operations \& Production Management, 25(1), 20-38.

Gopalakrishnan, S. \& Santoro, M. (2004). Distinguishing between knowledge transfer and technology transfer activities: the role of key organizational factors, IEEE Transactions on Engineering Management, 51(1), 57-69.

Grover, V. \& Kohli, R. (2012). Cocreating IT value: new capabilities and metrics for multiform environments, MIS Quarterly, 36(1), 225-232.

Gunasekaran, A. \& Ngai, E. W. T. (2004). Information systems in supply chain integration and management, European Journal of Operational Research, 159(2), 269-295.

Günsel, A. (2015). Research on Effectiveness of Technology Transfer from a Knowledge Based Perspective, Procedia - Social and Behavioral Sciences, 207, 777-785.

Hackius, N. \& Petersen, M. (2017). Blockchain in logistics and supply chain: Trick or treat?, In Proceedings of the Hamburg International Conference of Logistics (HICL), 23, Berlin (pp. 3-18).

Hair, J. F., Black, W. C., Babin, B. J. \& Anderson, R. E. (2017). Multivariate Data Analysis. Prentice Hall, Upper Saddle River, NJ.

Handfield, R. B. \& Bechtel, C. (2002). The role of trust and relationship structure in improving supply chain responsiveness, Industrial Marketing Management, 31(4), 367-382.

Hofmann, E., Strewe, U. M. \& Bosia, N. (2018). Supply Chain Finance and Blockchain Technology. Springer International, Heidelberg.

Hudson, M., Smart, A. \& Bourne, M. (2001). Theory and practice in SME performance measurement systems, International Journal of Operations \& Production Management, 21(8), 1096-1115.

Jedlitschka, A., Ciolkowski, M., Denger, C., Freimut, B. \& Schlichting, A. (2007). Relevant Information Sources for Successful Technology Transfer: A Survey Using Inspections as an Example. In First International Symposium on Empirical Software Engineering and Measurement (ESEM 2007), (pp. 3140). DOI: 10.1109/ESEM.2007.60

Khan, M. A. \& Salah, K. (2018). IoT security: Review, blockchain solutions, and open challenges, Future Generation Computer Systems, 82, 395-411.

Kshetri, N. (2018). Blockchain's role in meeting key supply chain management objectives, International Journal of Information Management, 39, 80-89.

Lin, C., He, D., Xinyi, H, Choo, K. W. R. \& Vasilakos, A. V. (2018). BSeIn: A blockchain-based secure mutual authentication with fine-grained access control system for industry 4.0, Journal of Network and Computer Applications, 116(15), 42-52.

Mason-Jones, R., Naylor, B. \& Towill, D. R. (2000). Lean, agile, or leagile? Matching your supply chain to the marketplace, International Journal of Production Research, 38(17), 4061-4070.

Mentzer, J. T., William DeWitt, W., Keebler, J. S., Min, S., Nix, N. W. \& Smith, C. D. \& Zacharia, Z. G. (2011). Defining Supply Chain Management, Journal of Business Logistics, 22(2), 1-25.

Michel, R. (2017). The evolution of the digital supply chain, Logistics Management, 2(5), 22-28.

Michna, A. (2009). The relationship between organizational learning and SME performance in Poland, Journal of European Industrial Training, 33(4), 356-370.

Mingxiao, D., Xiaofeng, M., Zhe, Z., Xiangwei, W. \& Qijun, C. (2017). A review on consensus algorithm of blockchain. In 2017 IEEE International Conference on Systems, Man, and Cybernetics (SMC), (pp. 2567-2572).

Nguyen, H., Onofrei, G., Harrison, N. \& Truong, D. (2020). The influence of cultural compatibility and product complexity on manufacturing flexibility and financial performance, Operations Management Research, 13(3-4), 1-14.

Nicotra, M., Romano, M., Giudice, M. \& Schllaci, C. E. (2018). The causal relation between entrepreneurial ecosystem and productive entrepreneurship: a measurement framework, The Journal of Technology Transfer, 43, 640-673.

Park, C.-W., Kim, C.-B. \& Sung-Min, P. (2017). A Study on the Relationship among Antecedence Factors of Agility Capacity, Agility Capacity, and Supply 
Chain Performance in Responsive Supply Chain: Focusing on Electronic and Telecommunication, Electric Industries in Daegu \& Kyungpook Area, Korean Journal of Logistics, 25(4), 155-180.

Pereira, J. V. (2009). The new supply chain's frontier: Information management, International Journal of Information Management, 29(5), 372-379.

Pezeshkan, A., Fainshmidt, S., Nair, A., Frazier, M. L. \& Markowski, E. (2016). An empirical assessment of the dynamic capabilities-performance relationship, Journal of Business Research, 69(8), 2950-2956.

Pilkington, M. (2016). Blockchain technology: Principles and Applications, in Research Handbook of Digital Transformations, Edward Elgar Publishing.

Popescu, D. I., Alexandru, A., Ceptureanu S. I. \& Ceptureanu E. G. (2018). Analysis of MSEs in ICT Domain from Bucharest - Ilfov County by Using Nonaka - Takeuchi Model, Studies in Informatics and Control, 27(1), 107-116. DOI: 10.24846/ v27i1y201811

Prahalad, C. K. \& Krishnan, M. S. (2008). The New Age of Innovation: Driving co-Created Value through Global Networks, McGraw Hill, New York, NY.

Prajogo, D. \& Olhager, J. (2012). Supply chain integration and performance: The effects of long-term relationships, information technology and sharing, and logistics integration, International Journal of Production Economics, 135(1), 514-522.

Premkumar, G., Ramamurthy, K. \& Saunders, C. S (2005). Information Processing View of Organizations: An Exploratory Examination of Fit in the Context of Interorganizational Relationships, Journal of Management Information Systems, 22(1), 257-294.

Qrunfleh, S. \& Tarafdar, M. (2013), Lean and agile supply chain strategies and supply chain responsiveness: the role of strategic supplier partnership and postponement, Supply Chain Management - An International Journal, 18(6), 571-582.

Rai, A., Patnayakuni, R. \& Seth, N. (2006). Firm Performance Impacts of Digitally Enabled Supply Chain Integration Capabilities, MIS Quarterly, 30(2), 225-246.

Reinartz, W., Krafft, M. \& Hoyer, W. D. (2004). The Customer Relationship Management Process: Its Measurement and Impact on Performance, Journal of Marketing Research, 41(3), 293-305.

Romano, D. \& Schmid, G. (2017). Beyond Bitcoin: A Critical Look at Blockchain-Based Systems, Cryptography, 1(2), 15.

Saberi, S., Kouhizadeh, M. \& Sarkis, J. (2018). Blockchain technology and its relationships to sustainable supply chain management, International Journal of Production Research, 57(7), 2117-2135.

Salvador, F., Forza, C., Rungtusanatham, M. \& Choi, T. Y. (2001), Supply chain interactions and timerelated performances: an operations management perspective, International Journal of Operations \& Production Management, 21(4), 461-475.

Scholtz-Reiter, B., Frazzon, E. M. \& Makuschewitz, T. (2010). Integrating manufacturing and logistic systems along global supply chains, CIRP Journal of Manufacturing Science and Technology, 2(3), 216-223.

Shah, R., Goldstein, S. M. \& Ward, P. T. (2002), Aligning supply chain management characteristics and interorganizational information system types: an exploratory study, IEEE Transactions on Engineering Management, 49(3), 282-292.

Shaw, B. (1988). Gaining Value added from Centres of Excellence in the UK Medical Industry, $R \& D$ Management, 18(2),123-130.

Shishodia, A., Verma, P. \& Dixit, V. (2019). Supplier Evaluation for Resilient Project Driven Supply Chain, Computers \& Industrial Engineering, 129, 465-478.

Sidik, I. G. (2012). Conceptual Framework of Factors Affecting SME Development: Mediating Factors on the Relationship of Entrepreneur Traits and SME Performance, Procedia Economics and Finance, 4, 373-383. DOI: 10.1016/S2212-5671(12)00351-6

Sigalas, C., Pekka E. V. B. \& Georgopoulos, N. (2013). Developing a measure of competitive advantage, Journal of Strategy and Management, 6(4), 320-342. DOI: 10.1108/JSMA-03-2013-0015

Soon, H. Q. \& Udin, M. Z. (2011). Supply chain management from the perspective of value chain flexibility: an exploratory study, Journal of Manufacturing Technology Management, 22(4), 506-526.

Svensson, G. (2000). A conceptual framework for the analysis of vulnerability in supply chains, International Journal of Physical Distribution \& Logistics Management, 30(9), 731-749.

Tapscott, D. \& Tapscott, A. (2017). How blockchain will change organizations, MIT Sloan Management Review, 58(2), 10-13.

Tipu, A. S. \& Fantazy, K. (2019). Effects of the attributes of supply chain openness on sustainable supply chain performance, International Journal of Productivity and Performance Management, 69(9), 2047-2068.

Tjahjono, B., Esplugues, C., Ares, E. \& Pelaez, G. (2017). What does Industry 4.0 mean to Supply Chain?, Procedia Manufacturing, 13, 1175-1182. 
Topal, B. \& Sahin, H. (2018). The Influence of Information Sharing in the Supply Chain Process on Business Performance: An Empirical Study, Studies in Informatics and Control, 27(2), 203-214. DOI: 10.24846/v27i2y201808

Ueno, Y., Zhang, J. \&Aoyama, K. (2017). Development of Performance Simulation Model by Making Indices of Supply Chain Capabilities, International Journal of Automation Technology, 11(2), 287-300.

van der Vaart, J. T. \& van Donk, D. P. (2008). A critical review of survey-based research in supply chain integration, International Journal of Production Economics, 111(1), 42-55.

Vickery, S. K., Jayaram, J., Droge, C. \& Calantone, R. (2003). The effects of an integrative supply chain strategy on customer service and financial performance: an analysis of direct versus indirect relationships, Journal of Operations Management, 21(5), 523-539.

Vukolić, M. (2015). The quest for scalable blockchain fabric: proof-of-work vs. BFT replication. In International Workshop on Open Problems in Network Security (pp. 112-125). Springer.

Wang, E., Tai, J. \& Grover, V. (2012). Examining the relational benefits of improved inter firm information processing capability in buyer supplier dyads, MIS Quarterly, 37(1), 149-173.
Williams, B. D., Roh, J., Tokar, T. \& Swink, M. (2013). Leveraging supply chain visibility for responsiveness: The moderating role of internal integration, Journal of Operations Management, 31(7-8), 543-554.

Winter, S. G. (2003). Understanding dynamic capabilities, Strategic Management Journal, 24(10), 991-995.

Wu, F., Yeniyurt, S., Kim, D. \& Cavusgil, S. T. (2006). The impact of information technology on supply chain capabilities and firm performance: A resourcebased view, Industrial Marketing Management, 35(4), 493-504.

Yli-Huumo, J., Ko, D., Choi, S., Park, S. \& Smolander, K. (2016). Where Is Current Research on Blockchain Technology? - A Systematic Review, PLoS One, 11(10): e0163477.

Yu, K., Cadeaux, J. \& Song, H. (2017). Flexibility and quality in logistics and relationships, Industrial Marketing Management, 62, 211-225.

Zheng, Z., Xie, S., Dai, H.-N., Chen X. \& Wang, H. (2016). Blockchain challenges and opportunities: a survey, International Journal of Web and Grid Services, 14(4), 352-375. 